\title{
Electrocardiogram features predictive of takotsubo syndrome
}

\author{
John E. Madias ${ }^{1,2}$ \\ Received: 1 July 2018 / Accepted: 17 July 2018 / Published online: 26 July 2018 \\ c) Springer-Verlag GmbH Germany, part of Springer Nature 2018
}

Sirs:

I read with great interest the paper by Gassanov et al. [1] focused on the electrocardiogram (ECG) differentiation of takotsubo syndrome (TTS) and acute myocardial infarction (AMI), based on data from 82 patients with TS and 141 patients with AMI. The authors were able to provide a diagnostic 6-point TTS score from the evaluation patient set, which was found to be valid in the validation cohort tested at another hospital, with excellent sensitivity and specificity for the TTS/AMI differentiation. I was particularly interested in the performance of ECG QRS amplitudes in the frontal and precordial leads, which were significantly lower in the TTS as compared to the AMI groups, in keeping with previous work [2, 3]. As the authors specified, they have considered the first ECG which was obtained "within $4 \mathrm{~h}$ after symptom onset with the mean symptom-to-ECG-time of $3.5 \mathrm{~h}$ " [1]. However, often transient loss of QRS voltage in limb and precordial leads occurs in the second ECG in patients with TTS [2, 3], and the authors may find interesting information by comparing the first with the second ECGs of their patients (particularly if the second ECG was recorded just a few hours after the first), although their objective was to create an ECG scoring system for the differentiation of TTS/AMI, to expedite decisions for further diagnostic testing (i.e., cardiac catheterization) and management [1].

Table 1 of the paper reveals that the evaluation group with a mean age of 68 years had a prevalence of diabetes mellitus (DM) of $13 \%$ and the validation group with a mean age of 65 years had a prevalence of DM of $11 \%$, with the corresponding prevalences of DM for the patients with AMI

John E. Madias

madiasj@nychhc.org

1 Icahn School of Medicine at Mount Sinai, New York, NY, USA

2 Division of Cardiology, Elmhurst Hospital Center, 79-01 Broadway, Elmhurst, NY 11373, USA being 47 and $37 \%$ [1]. These prevalences of DM in patients with TTS are in keeping with previous work [4, 5] suggesting that the prevalence of DM is lower in patients with TTS, than the one in the general population. In this vein, I will appreciate information provided by the authors about the prevalence of DM in subjects aged at mid- to late-60s in the territories surrounding Cologne and Gütersloh, Germany.

Acknowledgements No funding has been received for this work.

\section{Compliance with ethical standards}

Conflict of interest There are no conflicts of interest to disclose.

\section{References}

1. Gassanov N, Le MT, Caglayan E, Hellmich M, Erdmann E, Er F (2018) Novel ECG-based scoring tool for prediction of takotsubo syndrome. Clin Res Cardiol. https://doi.org/10.1007/s00392-0181314-3. [Epub ahead of print]

2. Madias JE (2014) Transient attenuation of the amplitude of the QRS complexes in the diagnosis of takotsubo syndrome. Eur Heart J Acute Cardiovasc Care 3:28-36 3

3. Guerra F, Giannini I, Pongetti G, Fabbrizioli A, Rrapaj E, Aschieri D, Pelizzoni V, Villani GQ, Madias JE, Capucci A (2015) Transient QRS amplitude attenuation is associated with clinical recovery in patients with takotsubo cardiomyopathy. Int J Cardiol 187:198-205 4

4. Madias JE (2016) Low prevalence of diabetes mellitus in patients with takotsubo syndrome: a plausible 'protective' effect with pathophysiologic connotations. Eur Heart J Acute Cardiovasc Care 5:164-170 5

5. Madias JE (2018) Diabetes mellitus prevalence in patients with takotsubo syndrome: the case of the brain-heart disconnect. Heart Lung 47:222-225 